\title{
A questão agrária brasileira sob a ótica da educação do campo
}

\author{
Carlos José Espíndola* \\ Paulo Henrique Schlickmann ${ }^{* *}$
}

\section{Resumo}

A partir das ocupações, realizadas na década de 80 do século XX, o Movimento Sem-Terra (MST) passou a delinear estratégias à construção de uma proposta pedagógica voltada para os homens do campo. Essas propostas colocavam-se como alternativas contra hegemônicas e procuravam dar um novo conteúdo teórico para a compreensão do [agro brasileiro. Em que pese a importância dessas experiências, faz-se necessário responder a uma questão: como a educação do campo analisa a questão agrária brasileira? Este texto, portanto, objetiva responder a esse questionamento.

Palavras-chave: Educação do campo; Reforma agrária; Agronegócio; Agricultura familiar.

The brazilian agrarian issue under rural education optics

\section{Abstract}

From occupations held in the 1980s of the twentieth century, the Landless Movement (MST) outlined strategies for building a pedagogical proposal focused on the country men. These proposals were positioned as counter-hegemonic alternatives and sought to offer a new theoretical content to the Brazilian agriculture understanding. Despite the experiences importance, it is necessary

Professor do Departamento de Geociências da UFSC e Programa de Pós- Graduação em Geografia

** Mestre em Geografia pelo Programa de Pós-Graduação em Geografia

Geosul, Florianópolis, v. 29, ESPECIAL, p 57-71, jul./dez. 2014 
ESPÍNDOLA, C.J. \& SCHLICKMANN, P.H. A questão agrária brasileira ...

to answer the following question: how does the countryside education analyze the Brazilian agrarian issue? Therefore, the text aims to answer that question.

Key words: Rural education; Agrarian reform; Agribusiness; Family agriculture.

\section{Introdução}

A agricultura brasileira, com cerca de 5,1 milhões de estabelecimentos, em uma área de 329 milhões de hectares, passou nos últimos cinquenta anos por profundas transformações estruturais $^{1}$. As mudanças indicam que a agricultura brasileira passou por um intenso processo de modernização com elevado aumento da produtividade não mais calcada no crescimento determinado pela incorporação de novas terras e mão de obra, mas sim de capital. Essa modernização, pós-1960, promoveu, ainda, com o aporte estatal, a centralização de diferentes capitais; a conquista de terras antes não ocupadas; a desarticulação da produção para o autoconsumo; a criação dos semiproletários agrícolas; a expansão do mercado interno; a liberação de mão de obra para o quadro urbanoindustrial; a ampliação da produção de alimentos; a inserção brasileira no mercado mundial de alimentos e a criação de um sistema nacional privado e estatal de ciência e tecnologia ${ }^{2}$.

${ }^{1}$ Entre 1970-2006, houve uma redução da população rural ocupada de 17,5 milhões para 16,5 milhões, uma redução da área média, um crescimento do produto em razão da produtividade total de fatores, um aumento do uso de máquinas de 204 mil para 820 mil, uma redução das áreas destinadas à pastagem, um aumento das áreas destinadas à lavoura e uma redução da área de lavoura por trator de 240,8 ha/t, em 1970, para 72,9 ha/t, em 2006 (IBGE, 2006).

${ }^{2}$ Essas transformações, como frutos do progresso técnico, forjaram novos segmentos produtivos a jusante e a montante da agricultura, denominados de cadeias de produção/comercialização/distribuição. Essas cadeias envolvem desde a fabricação de insumos, a produção agropecuária, a 
ESPÍNDOLA, C.J. \& SCHLICKMANN, P.H. A questão agrária brasileira ...

Ao mesmo tempo, o avanço do capitalismo no campo resultou na maior concentração da propriedade e da renda fundiária, na maior concentração da população nas áreas urbanas, na maior dominação do urbano sobre o rural, na marginalização e exclusão da agricultura camponesa, na priorização da agricultura capitalista baseada na monocultura, entre outros aspectos. Essas desigualdades renovaram, por um lado, as lutas dos camponeses pela terra, via reforma agrária, demandando linhas de créditos, assistência técnica, políticas públicas, etc.

Desde meados dos anos de 1980, o MST vem buscando formas de impulsionar o desenvolvimento rural. Em seu caderno de formação $\mathrm{n}^{\circ}$ 18, o MST afirma que "[...] é preciso romper com a cerca do latifúndio do analfabetismo e da educação burguesa, fazendo a reforma agrária também do saber e da cultura"3. Assim, em 1987, foi criado o setor de educação do MST que se tornaria "responsável pela organização e sistematização de propostas e práticas pedagógicas nas escolas localizadas nos assentamentos da reforma agrária e nos acampamentos" (SOUZA, 2008, p. 1094). Dentro dessa perspectiva, o MST passou a "[...] demandar do Estado iniciativas no âmbito da oferta de educação pública e da formação de profissionais para trabalhar nas escolas localizadas no campo" (SOUZA, 2008, p. 1090).

A partir disso, as discussões sobre educação do campo foram fortalecidas no $1^{\circ}$ Encontro Nacional de Educadores da Reforma Agrária (ENERA), realizado em 1997 na cidade de Brasília. Já em 1998 foi realizada, na cidade de Luziânia-GO a $1^{\text {a }}$ Conferência

transformação agroindustrial, os serviços de pesquisa, assistência técnica, transporte, comercialização, serviços portuários, distribuidores, bolsas, crédito e o consumo final (CONTINI et al., 2006).

${ }^{3}$ De acordo com os dados do censo de 2006 , cerca de $90 \%$ da população rural possuem qualificação inferior ao ensino fundamental (VIEIRA FILHO, 2008, p. 87). 
ESPÍNDOLA, C.J. \& SCHLICKMANN, P.H. A questão agrária brasileira ...

Nacional por uma Educação Básica do Campo ${ }^{4}$. O desfecho desses encontros foi a criação, em 1998, do Programa Nacional de Educação na Reforma Agrária (PRONERA) ${ }^{5}$.

Dois novos processos foram ainda fundamentais para a educação do campo. O primeiro foi a constituição do Plano Nacional de Educação (PNE), aprovado pelo Congresso Nacional em 2001, e o segundo foi a criação das Diretrizes Operacionais para a Educação Básica nas Escolas do Campo, regulamentadas em 2002, pelo Conselho Nacional de Educação.

Diante desse quadro, como a educação do campo analisa a questão agrária brasileira? Este texto, portanto, objetiva responder a essa questão, procurando ofertar subsídios para uma compreensão da realidade rural brasileira e contribuir para o debate sobre educação do campo.

\section{A educação do campo e a interpretação da questão agrária brasileira}

É inegável o papel que vem desempenhando a educação do campo no Brasil. Contudo, a interpretação sobre a realidade agrária brasileira acaba difundindo ideias que precisam ser relativizadas e analisadas à luz da realidade concreta. Assim, apontamos quatro

${ }^{4}$ Cabe destacar que, em 1996, a Lei de Diretrizes e Bases da Educação (LDB) afirma em seu artigo 28 a possibilidade de adequação curricular e metodologias apropriadas ao meio rural. Em seu artigo $1^{\circ}$, a LDB afirma que "a educação deve abranger os processos formativos que se desenvolvem na vida familiar, no trabalho nas instituições de ensino e pesquisa, nos movimentos sociais e organizações da sociedade civil e nas manifestações culturais".

5 No PRONERA, existem vários projetos de "educação de jovens e adultos, visando à alfabetização, escolarização e capacitação dos trabalhadores dos assentamentos da reforma agrária, além de projetos de formação inicial como a pedagogia da Terra e a licenciatura em educação do campo" (SOUZA, 2008, p. 1091). 
ESPÍNDOLA, C.J. \& SCHLICKMANN, P.H. A questão agrária brasileira ...

grandes eixos interpretativos da educação do campo sobre o espaço agrário brasileiro.

$\mathrm{O}$ primeiro eixo interpretativo refere-se ao papel desempenhado pelo mercado. Segundo as matrizes teóricas da educação do campo, a nova agricultura que está sendo criada pelos assentamentos e pela "nova sociedade" é a sua não vinculação com o mercado, pois o mercado é dominado pela lógica capitalista.

Nos primórdios da sociedade humana, a economia, como uma soma da produção e da circulação dos bens produzidos (mercadorias), era uma economia natural. Os bens produzidos destinavam-se a satisfazer as necessidades reais e/ou fictícias dos próprios produtores. Essas comunidades não praticavam a troca, mas sim produziam valores de uso. Heródoto, ao descrever os líbios e os cartagineses, falava em um "comércio silencioso" no interior da própria comunidade. Segundo Marx (1989), o processo de troca de mercadorias não aparece no seio das comunidades primitivas, mas onde estas terminam: em suas fronteiras, nos pontos de contato com outras comunidades. Aí começa o comércio por troca e daí se estende ao interior da comunidade, sobre a qual, então, atua de modo dissolvente. Assim, nas formações sociais précapitalistas (asiáticas, escravistas e feudais), continuava predominando a economia natural, mas o desenvolvimento das forças produtivas e da divisão social do trabalho possibilitou a crescente produção de bens destinados ao mercado. Contudo, essa produção para o mercado ocupava uma posição intermediária. É somente nas formações sociais capitalistas que a economia mercantil torna-se dominante.

A questão do mercado para o desenvolvimento do capitalismo foi um tema amplamente estudado por Lênin (1982). Nesse sentido, de acordo com Lênin (1982), a decomposição do campesinato cria por si só o mercado para a agricultura mercantil, pois se alargam as bases da divisão social do trabalho manufatureiro. Num segundo estágio, quando se intensifica a concorrência entre os produtores manufatureiros independentes, estará consolidada a diferenciação social na economia capitalista, 
ESPÍNDOLA, C.J. \& SCHLICKMANN, P.H. A questão agrária brasileira ... justamente impulsionada pelo mercado relativamente em expansão. É o progressivo desenvolvimento da divisão social do trabalho, alavancado pela especialização necessária à superação concorrencial, que constitui o elemento fundamental no processo de formação de um mercado interno para o capitalismo, onde a agricultura torna-se um elo da imensa divisão social e técnica do trabalho.

A modernização agrícola no Brasil, pós-1960 constituiu uma geração de produtores que passaram a se orientar por uma racionalidade técnica completamente diferente do passado. São agricultores motivados pelo lucro decorrente dos ganhos de produtividade do capital e não mais pelo aumento da área cultivada e/ou pela incorporação de mão de obra ${ }^{6}$. Isso levou, por um lado, à concentração em produções em que o diferencial é a escala de produtos e a mecanização e, por outro, a integração da pequena e média propriedade para o cultivo em escalas. A consolidação dessa estrutura passou a garantir uma oferta de alimentos e matériasprimas que se destinam a uma demanda crescente.

Assim, as teses afirmativas de que as famílias rurais, marcadas por práticas comunitárias, pelo tradicionalismo rural, pelas relações de parentesco, pelo direito costumeiro, pelas manifestações culturais e pela relação direta com a terra, reconstroem uma vida comunitária não mercantil "não resiste a nenhuma verificação empírica" (NAVARRO, 2008, p. 26). Enquanto se fica idealizando sobre a produção de alimentos "independentes", "não capitalistas", os grandes conglomerados oligopolizam a produção de semente dos principais produtos agrícolas e a genética dos rebanhos de produção de carne e de leite (SAMPAIO; BROIETTI; MEDEIROS, 2005, p. 14).

${ }^{6}$ A modernização da agropecuária precipitou a crise dos pequenos produtores, do mesmo modo que a agricultura moderna necessitava cada vez menos de mão de obra. $O$ resultado foi a criação de um semiproletário agrícola e um excedente populacional no campo que se viu obrigado a demandar as cidades (RANGEL, 2000). 
ESPÍNDOLA, C.J. \& SCHLICKMANN, P.H. A questão agrária brasileira ...

O segundo eixo de interpretação sobre a realidade brasileira recai da tese da reprodução do campesinato e da utilização do termo pela educação do campo. Oliveira (1987), um dos grandes estudiosos da geografia agrária brasileira, afirma que o processo contraditório de reprodução ampliada do capital, além de redefinir antigas relações de produção, engendra relações não capitalistas igual e contraditoriamente necessárias à sua reprodução ${ }^{7}$. Essa é uma assertiva indiscutível. Mas, ressalta-se que o processo de criação e recriação do campesinato pelo capitalismo pode ser comprovado somente em curto prazo, pois as tendências indicam que, em meados do século XXI, mais de $60 \%$ da população mundial será urbanizada. No Brasil, há quarenta anos, $60 \%$ da população total vivia na área rural, hoje não passa de $15 \%$. Ademais, ao recriar não recria nas mesmas condições herdadas.

Quanto à utilização da terminologia camponesa é necessário ressaltar que o transplante da concepção de camponês de outras realidades históricas, do fim do século XIX e do começo do século $\mathrm{XX}$, "é um procedimento que encontra dificuldades para enquadrar e explicar a situação das lutas sociais no meio rural brasileiro" (MARTINS, ano apud NAVARRO, 2008, p. 22). Pode-se com certeza afirmar que as profundas mudanças da sociedade brasileira nas últimas décadas produziram efeitos diversos, em que o homem rural deixou de ser aquele camponês retrógrado, para integrar-se, do seu modo, ao mundo capitalista, bem como ao mercado e à modernização. Nesse sentido, qualquer homem ou classe social têm seu caráter particular de sociabilidade ${ }^{8}$.

${ }^{7}$ Essas teses viriam contrapor-se aos trabalhos clássicos que afirmavam que o processo de diferenciação social ampliaria o assalariamento no campo (LÊNIN, 1982) e que a agricultura familiar é inferior diante da agricultura patronal (KAUTSKY, 1986). As críticas aos clássicos aparecem inicialmente nas análises de Chayanov sobre a persistência das unidades camponesas de produção na sociedade russa.

${ }^{8}$ Em relação à sociabilidade, ver "A Sociabilidade do Homem Simples" (MARTINS, 2011). 
ESPÍNDOLA, C.J. \& SCHLICKMANN, P.H. A questão agrária brasileira ...

O terceiro eixo interpretativo da educação do campo sobre o rural brasileiro diz respeito ao fato de que a produção agrícola moderna está totalmente dominada pela monocultura latifundiária voltada ao mercado externo em detrimento do mercado interno. O alerta que se faz é que tanto Lênin (1982) como Kautsky (1986) já haviam demonstrado que, no processo de modernização da agricultura, a grande produção proporciona a penetração das relações capitalistas no campo e o aprofundamento das diversas relações. O desenvolvimento do capitalismo no campo traz as possibilidades técnicas (química, física e biológica) que distanciam as condições de produção da fazenda e da pequena produção ${ }^{9}$.

Entretanto, em determinadas cadeias produtivas, como aves, suínos, leite, fumo, dezenas de pequenas propriedades apresentamse dinâmicas e progressistas com elevada composição de capital, rompendo as múltiplas barreiras técnicas. Por sua vez, a racionalização e o aumento da composição orgânica promoveram, por um lado, um processo de diferenciação no seio desses pequenos produtores e, por outro, um grau de concentração da produção em um pequeno número de produtores.

As análises realizadas por Alves (2010) a respeito da produção agropecuária brasileira indicam que o grupo de valor, cuja produção mensal é de dois a menos de dez salários mínimos, corresponde a $18,86 \%$ dos estabelecimentos totais e contribui para $11,08 \%$ do valor da produção nacional. Somando-se o grupo com valor da produção inferior a 25 salários mínimos, totaliza-se $15,11 \%$ da produção total, envolvendo $91,81 \%$ dos

${ }^{9}$ Nos EUA, em 1944 existiam 5,9 milhões de agricultores; já em 1982 esse número caiu para 2,2 milhões. Nesse mesmo ano, cerca de trezentos mil agricultores $(13,5 \%$ do total) respondiam por $72,6 \%$ das vendas e $98,5 \%$ da venda líquida agrícola. Em 1997, o número de agricultores já havia caído para 1,9 milhão e apenas 8,2\% deles representavam $72,1 \%$ das vendas. Portanto, a tendência de longo prazo é que os grandes produtores familiares demonstrem uma superioridade sobre os pequenos produtores familiares (GONÇALVES, 2005). 
ESPÍNDOLA, C.J. \& SCHLICKMANN, P.H. A questão agrária brasileira ... estabelecimentos. Logo, 8,19\% deles são responsáveis por 84,89\% da produção. Além disso, os que produziram mais de duzentos salários mínimos mensais em números de 22.188, representando apenas $0,43 \%$ dos estabelecimentos, foram responsáveis por 51,34\% da produção (ALVES, 2010, p. 284).

$\mathrm{Na}$ produção de leite, a grande maioria $(80,41 \%)$ dos estabelecimentos (1.084.944) produziu menos de cinquenta litros por dia e é responsável por $26,7 \%$ da produção, o restante produziu $73,3 \%$. Na produção de milho, 90,99\% dos estabelecimentos (1.847.052) produziram 4.210.099,15 toneladas, o que representa apenas $9,96 \%$ da produção, enquanto $1,57 \%$ do total dos estabelecimentos produziu 28.882.575,67, ou seja, 68,31\% da produção. Percebe-se, por conseguinte, que a produção está concentrada num pequeno número de estabelecimentos que são a base do agronegócio.

A tendência à concentração da produção em uns menores números de produtores está também presente na produção de café, feijão preto, feijão de cor, etc. Assim, a competitividade se dá pela comparação das escalas (áreas de lavouras com o mesmo capital fixo disponível) e não pelo tamanho da propriedade ${ }^{10}$. De outro modo, cabe destacar que a produção entre produtores familiares e não familiares apresenta índice de produtividade diferenciado. $\mathrm{Na}$ produção de feijão, a produtividade medida em $\mathrm{kg}$ por hectare apresenta, para a agricultura familiar, $618 \mathrm{~kg} / \mathrm{ha}$, enquanto nas não familiares é de $1.151 \mathrm{~kg} / \mathrm{ha}$. Na produção de arroz, é de 2.741 $\mathrm{kg} / \mathrm{ha}$, contra $5.030 \mathrm{~kg} / \mathrm{ha}$, enquanto a mandioca é de $5.770 \mathrm{~kg} / \mathrm{ha}$ contra $7.541 \mathrm{~kg} / \mathrm{ha}$.

${ }^{10}$ Nos Estados Unidos, o número de fazendas com vendas anuais acima de US\$ 500 mil dólares aumentou 23\% de 1997 a 2002. Trezentas e cinquenta mil fazendas de tamanho médio, que cultivam $40 \%$ das terras produtivas, estão a caminho de desparecer. As fazendas de tamanho médio, com vendas de US\$ 50 mil a US\$ 500 mil, estão em rápido declínio. Não é difícil imaginar que a maioria das fazendas de tamanho médio terá desaparecido em mais uma década (GONÇALVES, 2005). 
ESPÍNDOLA, C.J. \& SCHLICKMANN, P.H. A questão agrária brasileira ...

Já a afirmação de que a agricultura moderna é totalmente voltada para o mercado externo é desprovida de comprovação empírica, pois produtos como o arroz, feijão, milho e carne, básicos para o consumo da classe trabalhadora, experimentaram o desenvolvimento de novas técnicas e sementes, elevando os índices de produtividade. Cabe ressaltar ainda que, do total do produto do agronegócio, apenas 45\% é exportado, e os setores exportadores são os que mais desenvolveram o mercado interno nas últimas décadas (laranja, frango, açúcar, frutas, soja, entre outros) (SAMPAIO; BROIETTI; MEDEIROS, 2005).

É bem verdade que nos últimos anos as commodities agropecuárias tiveram espetacular desempenho exportador entre 2000-2011. Dentre os maiores índices de expansão do quantum exportado, nesse período, destacam-se açúcar bruto $363 \%$, carne bovina $333 \%$ e carne de frango $294 \%$, e a soja com $286 \%$. Contudo, o sucesso dos produtores de coommodities está na exploração de economias de escala e escopo, nos ganhos de produtividade, na racionalização dos processos produtivos, no acesso a recursos naturais, nas condições de infraestrutura e em logística.

O quarto eixo definidor da interpretação sobre a questão agrária assenta-se na ideia de reforma agrária. É indiscutível que o tema reforma agrária sempre esteve presente no debates da sociedade brasileira e nos intérpretes do Brasil, quer sejam conservadores, quer progressistas. Entretanto, faz-se necessário historicizar a questão. É importante ressaltar que a realização ou não da reforma agrária deve estar associada às características sociais e econômicas da época na qual é proposta. Logo, não seria bandeira de todos os tempos.

Nos anos de 1930, acreditava-se na reforma agrária como uma necessidade indispensável ao desenvolvimento industrial brasileiro. Entretanto, o Brasil industrializou-se sem a reforma agrária. Segundo Rangel (2000, p. 231),

“[...] contrariamente ao que nós, revolucionários brasileiros dos anos 30, julgávamos, a industrialização do Brasil seria 
ESPÍNDOLA, C.J. \& SCHLICKMANN, P.H. A questão agrária brasileira ...

possível, mesmo sem reforma agrária. A via prussiana, mudando que deveria ser mudado, substitui o latifúndio feudal pelo latifúndio capitalista e não apenas possibilitou a industrialização do País como permitiu a essa industrialização um impulso extraordinário e energético”.

Essa industrialização fazia-se com o rompimento do complexo rural que criava uma superpopulação rural relativa que se transformava em superpopulação urbana. O capitalismo brasileiro recruta sua mão de obra num mercado convulsionado por todas essas manifestações de desagregação da velha estrutura agrária (feudal) e de sua nova estrutura agrária (capitalista). Isso importa na formação de uma oferta excessiva de mão de obra, a qual deprime o poder de barganha das massas trabalhadoras dos setores capitalistas (RANGEL, 1986). Foi então, nesse contexto, que o capitalismo brasileiro foi desenvolvendo-se e a reforma agrária postergada.

Conforme Rangel (2000, p. 126) “[...] a reforma agrária, capítulo essencial da revolução democrático-burguesa, indispensável para ampliação do mercado interno e, principalmente, para a estruturação do mercado da mão-de-obra, teria que ser postergada por toda uma etapa do desenvolvimento brasileiro". Mesmo assim, Rangel identificou que a crise agrária dos anos 60 era um obstáculo ao desenvolvimento do capitalismo brasileiro. Contudo, o autor (1986, p. 46) considerava que "nada é mais ilusório do que esperar que a burguesia - ligada ao latifúndio, inclusive por laços de sangue - rompa seu pacto de poder com o latifúndio".

Nos anos de 1980 e 1990, diante da crise econômica, a ideia de reforma agrária retorna aos debates acadêmicos. Todas as formulações teóricas defendiam, a reforma agrária para o desenvolvimento da agricultura, sobretudo familiar. A defesa da reforma agrária para o desenvolvimento da agricultura familiar deriva da necessidade de desafogar os minifundistas, oferecendolhes a oportunidade de serem agricultores familiares viáveis; uma 
ESPÍNDOLA, C.J. \& SCHLICKMANN, P.H. A questão agrária brasileira ...

reforma agrária que transforme arrendatários em proprietários; uma reforma agrária que ofereça terra aos filhos dos pequenos proprietários (VEIGA, 1994, p. 91).

A ideia de reforma agrária para o desenvolvimento da agricultura familiar é descabida de conteúdo econômico. Seria absurdo continuar a pensar em agricultura como atividade caracterizada pela tecnologia mais primitiva de todos os setores do sistema econômico, condenada a contentar-se com os contingentes de mão de obra residual. Isto é, como aquela atividade, que, por força do seu despreparo, ainda não se houvesse sentido atraída pelos setores progressivos de ponta (RANGEL, 2000, p.159-160).

Em outros termos, seria um equívoco supor que a propriedade familiar é a alternativa para a fazenda capitalista. Quando por outros motivos não fosse: (a) porque, não obstante a enormidade territorial do país é escassa, as terras agricultáveis com os meios da família camponesa, sem máquinas, corretivos químicos, mão de obra assalariada e tecnologia moderna; (b) porque a quantidade de terras a desapropriar para tal programa ultrapassa largamente os meios financeiros do Estado. Seria como correr atrás da própria sombra, sem poder alcançá-la jamais, pois que a entrada do Estado no mercado fundiário - como comprador e não supridor de terras que era - promoveria a elevação do preço desse fator, reduzindo o poder aquisitivo real dos recursos alocados para tal fim. Essa reforma - supondo-se que se justificasse economicamente, isto é, que não fosse um retrocesso -, teria de se assentar na expropriação, não na desapropriação (RANGEL, 2000, p. 192-193).

A proposta, portanto, da reforma agrária para o desenvolvimento da agricultura familiar é apenas política, uma vez que possibilita o acesso desses assentados (classificado de familiar) a fundo públicos. De acordo com Navarro (2010, p. 33), enquanto o Estado brasileiro for capaz de ampliar os recursos financeiros e a implementação de políticas mais específicas para esse amplo setor social da população rural, dificilmente se desenvolverá, entre os 
ESPÍNDOLA, C.J. \& SCHLICKMANN, P.H. A questão agrária brasileira ...

"familiares", a percepção acerca de sua condição social desigual vis-à-vis os grandes proprietários de terra.

Se a reforma agrária não deve ser pensada para o desenvolvimento da agricultura familiar, como devemos pensá-la? A reforma agrária deve ser orientada para viabilizar uma produção complementar, deixando a grande produção agrícola para o mercado a cargo da fazenda capitalista com mão de obra assalariada. Essa proposta, entrou, há muito, na ordem natural das coisas (RANGEL, 2000, p. 228-229). Trata-se da criação de um pequeno lote para o assalariamento da moderna fazenda capitalista, fora da fazenda, em terra pública. Isso, por sua vez, tenderá a resolver o problema da escassez sazonal de mão de obra nas áreas de monocultura desenvolvida, como por exemplo, no Centro-Sul do Brasil.

\section{Conclusão}

Esse texto procurou demonstrar que, a partir das ocupações realizadas pelo MST, nos anos de 1980, o movimento passou a delinear estratégias à construção de uma educação do campo. Por inegável que sejam os esforços da educação do campo na visualização e apreensão da realidade rural brasileira, algumas questões precisam ser relativizadas e historicizadas, partindo do concreto, pois, quando os conceitos e as ideias são forjados pelo pensamento (consciência), é porque a realidade, de alguma maneira, já o pôs à disposição dessa consciência. Segundo Marx (1989), por mais que as categorias exprimem formas da existência, isso só é possível uma vez que o concreto seja seu ponto de partida. Portanto, procuramos contribuir para o debate propondo, com base na realidade concreta, uma releitura teórica e consubstanciada em dados, do que é o espaço agrário brasileiro. 
ESPÍNDOLA, C.J. \& SCHLICKMANN, P.H. A questão agrária brasileira ...

\section{Referências bibliográficas}

ALVES, E. ROCHA, D. P. In: Org. GASQUES, J. G. et al. Agricultura brasileira desempenho, desafios e perspectivas. IPEA: Brasília, 2010. p. 273-290.

BRASIL. Plano Nacional de educação. MEC: Brasília, 2001.

BRASIL, LDB. Lei ${ }^{0}$ 9394/96. Lei de Diretrizes e Bases da Educação Nacional. Disponível em: $<w w w . m e c . g o v . b r>$. Acesso em: 17 set. 2013.

CONTINI, Elísio et al. Evolução recente e tendências do agronegócio. In: Revista de Política Agrícola no 1. Brasília, 2006.

GONÇALVES, José S. A agricultura sob a égide do capital financeiro: passo rumo ao aprofundamento do desenvolvimento dos agronegócios. In: Informações Econômicas, v. 35, n. 4. São Paulo, 2005.

KAUTSKY, K. A Questão Agrária. São Paulo: Nova Cultural, 1986.

LÊNIN, V. I. O Desenvolvimento do Capitalismo na Rússia. São Paulo: Abril, 1982.

MARX, K. O Capital. São Paulo: Hucitec, 1989.

MARTINS, J. S. O Cativeiro da terra. São Paulo: Hucitec, 1975.

. A Sociabilidade do Homem Simples. 3. ed. São Paulo: Contexto, 2011.

NAVARRO, Z. A. "Nunca cruzaremos este rio" - A estranha associação entre o poder do atraso, a história lenta e a "sociologia 
ESPÍNDOLA, C.J. \& SCHLICKMANN, P.H. A questão agrária brasileira ...

militante", e o ocaso da reforma agrária no Brasil. REDES, Santa Cruz do Sul, v. 13, n. 2, p. 5-51, maio/ago. 2008.

OLIVEIRA, A. V. Modo capitalista de produção e agricultura. São Paulo: Ática, 1987.

. Economia: Milagre e Anti-Milagre. 2. ed. Rio de Janeiro: Jorge Zahar, 1986.

RANGEL, I. Questão agrária industrialização e crise urbana no Brasil. Rio Grande do Sul: ed. UFRGS, 2000.

SAMPAIO, F. S; BROIETTI, M. H; MEDEIROS, M. C. Dinâmica Capitalista na Agricultura Brasileira: Acumulação e relações de trabalho. Cadernos Geográficos - nº 11, maio 2005.

SOUZA, M. A. Educação do campo: Políticas, práticas pedagógicas e produção científica. Educ. Soc., Campinas, v. 29, n. 105, p. 1089-1111, set./dez. 2008.

VEIGA, J. E. O desenvolvimento agrícola: uma visão histórica. São Paulo: Hucitec/Edusp, 1991.

VIEIRA FILHO, J. E. R.; CONCEIÇÃO, J. C. P. Censo agropecuário 2006: Uma crítica ao recorte metodológico. Brasília: Ipea, 2010 (Radar, n. 6).

Recebido em

Aceito em 